\title{
Are clinical trial eligibility criteria an accurate reflection of a real-world population of advanced non-small-cell lung cancer patients?
}

\author{
K. Al-Baimani $\mathrm{MD}^{*}{ }^{*}$ H. Jonker $\mathrm{MSc}^{*}{ }^{*} \mathrm{~T}$. Zhang $\mathrm{PhD}^{\dagger}{ }^{\dagger}$ G.D. Goss $\mathrm{MD}^{* \dagger}{ }^{\dagger}$ S.A. Laurie $\mathrm{MD}^{* \dagger}$ \\ G. Nicholas $\mathrm{MD}^{* \dagger}$ and P. Wheatley-Price $\mathrm{MBChB} \mathrm{MD}^{* \dagger}$
}

\begin{abstract}
Background Advanced non-small-cell lung cancer (NSCLC) represents a major health issue globally. Systemic treatment decisions are informed by clinical trials, which, over years, have improved the survival of patients with advanced NSCLC. The applicability of clinical trial results to the broad lung cancer population is unclear because strict eligibility criteria in trials generally select for optimal patients.
\end{abstract}

Methods We performed a retrospective chart review of all consecutive patients with advanced NScLC seen in outpatient consultation at our academic institution between September 2009 and September 2012, collecting data about patient demographics and cancer characteristics, treatment, and survival from hospital and pharmacy records. Two sets of arbitrary trial eligibility criteria were applied to the cohort. Scenario A stipulated Eastern Cooperative Oncology Group performance status (ECOG PS) 0-1, no brain metastasis, creatinine less than $120 \mu \mathrm{mol} / \mathrm{L}$, and no second malignancy. Less-strict scenario B stipulated ECOG Ps 0-2 and creatinine less than $120 \mu \mathrm{mol} / \mathrm{L}$. We then used the two scenarios to analyze treatment and survival of patients by trial eligibility status.

Results The 528 included patients had a median age of 67 years, with $55 \%$ being men and $58 \%$ having adenocarcinoma. Of those 528 patients, 291 received at least 1 line of palliative systemic therapy. Using the scenario A eligibility criteria, $73 \%$ were trial-ineligible. However, $46 \%$ of "ineligible" patients actually received therapy and experienced survival similar to that of the "eligible" treated patients (10.2 months vs. 11.6 months, $p=0.10)$. Using the scenario B criteria, only $35 \%$ were ineligible, but again, the survival of treated patients was similar in the ineligible and eligible groups (10.1 months vs. 10.9 months, $p=0.57$ ).

Conclusions Current trial eligibility criteria are often strict and limit the enrolment of patients in clinical trials. Our results suggest that, depending on the chosen drug, its toxicities and tolerability, eligibility criteria could be carefully reviewed and relaxed.

Key Words Non-small-cell lung cancer, NSCLC, clinical trial eligibility

Curr Oncol. 2018 Aug;25(4):e291-e297

www.current-oncology.com

\section{INTRODUCTION}

Lung cancer is the most common cancer in the world and the leading cause of cancer death worldwide ${ }^{1,2}$. Although 5 -year survival in lung cancer has slowly improved to approximately $18 \%$ in 2011 from $12 \%$ in the $1970 \mathrm{~s}^{1}$, the disease remains lethal for most ${ }^{1,3}$.

Clinical trials have undoubtedly improved the outcomes of NSCLC treatment in both early- and late-stage disease ${ }^{4-11}$. However, fewer than $5 \%$ of all cancer patients participate in clinical trials $5,12-14$. Lung cancer patients represent only about $12.5 \%$ of all cancer clinical trial participants ${ }^{14}$, being 3rd in participation after breast and colorectal cancer patients, which demonstrates a true underrepresentation of lung cancer despite its remarkable epidemiology and lethality ${ }^{15,16}$.

One important obstacle to participation is the high selectivity of lung cancer clinical trials, which often have 
very restrictive eligibility criteria ${ }^{17-19}$. In fact, studies show that eligibility for a trial might require meeting as many as 44 criteria $^{19-21}$. Restrictive eligibility not only constitutes a barrier to clinical trial enrolment, but also creates other problems, including difficulty in generalizing results to the broader patient population ${ }^{22-28}$.

In the present study, we took an existing dataset of patients with advanced NSCLC that had previously been reported $^{29}$. We then used hypothetical clinical trial eligibility criteria to explore how many patients might be trial-eligible. We further assessed how outcomes varied between patient groups based on their trial eligibility and treatments actually received.

\section{METHODS}

\section{Patient Data}

After ethics approval, we performed a chart review of all patients with de novo advanced NSCLC (stage IIIB palliative and all stage IV) seen in the outpatient department at The Ottawa Hospital Cancer Centre between September 2009 and September 2012. The Ottawa Hospital Cancer Centre is an academic centre that is the sole provider of medical and radiation oncology services to a population of approximately 1.5 million in Eastern Ontario.

Data collected from hospital and pharmacy records included patient demographics, cancer characteristics, treatment details, and survival information. The primary analysis has previously been reported ${ }^{29}$.

\section{Clinical Trial Criteria}

We designed two clinical trial eligibility scenarios and then assessed how many patients in the cohort would have been "trial eligible" based on the inclusion criteria in each scenario. Subsequently, for each scenario, we compared the trial-eligible and -ineligible patients, the proportion of each group that received systemic therapy, and survival in the two groups.

Scenario A had more-strict eligibility criteria. Patients had to have an Eastern Cooperative Oncology Group performance status (PS) of 0 or 1 , absence of brain metastasis, creatinine less than $120 \mu \mathrm{mol} / \mathrm{L}$ (approximately 1.5 times the upper limit normal), and absence of a second malignancy.

Scenario B had less-strict eligibility criteria: Eastern Cooperative Oncology Group Ps 0-2 and creatinine less than $120 \mu \mathrm{mol} / \mathrm{L}$. If data relating to the eligibility criteria were missing, the patient was excluded from the analysis. Eastern Cooperative Oncology Group Ps was missing for $8 \%$ of patients, and baseline creatinine, for $2 \%$.

\section{Statistical Methods}

For this retrospective analysis, the chi-square test was applied. The survival analysis used the Kaplan-Meier method. All analyses were conducted using the SAS software application (version 9.3: SAS Institute, Cary, NC, U.S.A.).

\section{RESULTS}

The full descriptive analysis for this cohort of patients was reported in a previous publication ${ }^{29}$. In brief, 528 patients were included in the study (Table I). Median age in the cohort was 67.5 years; $55 \%$ of all patients were men; $43 \%$ were current smokers.

Of all NSCLCs, $58 \%$ were adenocarcinomas; only $22 \%$ were squamous cell carcinomas. Patients with stage IV disease represented $93 \%$ of the population; the remaining

TABLE I Demographic data for the study cohort

\begin{tabular}{|c|c|}
\hline Variable & Value \\
\hline Patients (n) & 528 \\
\hline \multicolumn{2}{|l|}{ Age at diagnosis (years) } \\
\hline Median & 67.5 \\
\hline Range & $34.9-89.7$ \\
\hline \multicolumn{2}{|l|}{$\operatorname{Sex}[n(\%)]$} \\
\hline Men & $292(55)$ \\
\hline Women & $236(45)$ \\
\hline \multicolumn{2}{|l|}{ ECOG PS $[n(\%)]$} \\
\hline 0 & $46(9)$ \\
\hline 1 & $220(42)$ \\
\hline 2 & $111(21)$ \\
\hline 3 & $92(17)$ \\
\hline 4 & $19(4)$ \\
\hline Unknown & $40(8)$ \\
\hline \multicolumn{2}{|l|}{ Smoking status $[n(\%)]$} \\
\hline Current smoker & $228(43)$ \\
\hline Ex-smoker & $257(49)$ \\
\hline Never-smoker & $37(7)$ \\
\hline Unknown & $6(1)$ \\
\hline \multicolumn{2}{|l|}{ Weight loss [ $n(\%)]$} \\
\hline$<5 \%$ & $235(45)$ \\
\hline$>5 \%$ & $255(48)$ \\
\hline Unknown & $38(7)$ \\
\hline \multicolumn{2}{|l|}{ Histologic subtype $[n(\%)]$} \\
\hline Adenocarcinoma & $308(58)$ \\
\hline Large-cell & $27(5)$ \\
\hline Mixed & $1(0.2)$ \\
\hline Other NSCLC & $29(6)$ \\
\hline Squamous cell & $118(22)$ \\
\hline Unknown & $45(9)$ \\
\hline \multicolumn{2}{|l|}{ Stage $[n(\%)]$} \\
\hline IIIB & $35(7)$ \\
\hline IV & $493(93)$ \\
\hline \multicolumn{2}{|l|}{ Reason for no CTx (if stated) [ $n(\%)]$} \\
\hline Poor performance status & $158(67)$ \\
\hline Age & $3(1)$ \\
\hline Comorbidities & $5(2)$ \\
\hline Patient choice & $49(23)$ \\
\hline Others & $22(9)$ \\
\hline
\end{tabular}

ECOG PS = Eastern Cooperative Oncology Group performance status; NSCLC $=$ non-small-cell lung cancer; $\mathrm{CTx}=$ chemotherapy. 
$7 \%$ had stage IIıв disease and were treated with palliative intent. Half the patients had a Ps of 0 or 1 .

Nearly half the patients ( $n=237,45 \%$ ) did not receive any systemic therapy. Treated patients were younger (median age: 64.8 years vs. 71 years for untreated patients, $p<$ $0.0001)$. A platinum doublet was the most common firstline therapy (88\%); pemetrexed-docetaxel was the most common therapy in the second-line setting.

Only $5 \%$ of the patients participated in a clinical trial for any given line of therapy. In 89 patients (17\%), a second malignancy had been diagnosed. In about 40 patients, creatinine was elevated above $120 \mu \mathrm{mol} / \mathrm{L}$, and 16 of them were still treated with chemotherapy.

\section{Survival Analysis}

\section{Scenario A}

Table II presents the patient demographic data for scenario A by trial eligibility. Using scenario A (strict criteria), only $27 \%$ of the patients ( $n=144$ ) would have been trialeligible. Of those 144 patients, 113 (78\%) were treated with at least 1 line of systemic therapy. Of the 384 patients
(73\%) who were not eligible, 178 (46\%) were still treated with systemic therapy (Table III).

The patients who were treated experienced similar median overall survival (os) regardless of whether they were trial-eligible or -ineligible (11.6 months vs. 10.2 months, $p=0.1$ ). However, compared with ineligible untreated patients, the eligible untreated patients experienced significantly superior survival (8.1 vs. 3.8 months, $p=0.003$, Table Iv, Figure 1).

\section{Scenario B}

Table v presents the patient demographic data for scenario B by trial eligibility. Using scenario B (relaxed criteria), more than half the patients $(65 \%, n=343)$ would have been trial-eligible. Of those 343 patients, 240 (70\%) were treated (Table III). Of the 185 patients (35\%) who were not eligible, only 51 (28\%) were still treated (Table III).

As in scenario A, survival for the patients who received systemic therapy was similar whether they were trialeligible or -ineligible (10.9 months vs. 10.1 months, $p=0.57$ ). However, compared with ineligible untreated patients, the eligible untreated patients experienced significantly better

TABLE II Demographic data, scenario A

\begin{tabular}{|c|c|c|c|c|}
\hline \multirow[t]{3}{*}{ Variable } & \multicolumn{4}{|c|}{ Patient group } \\
\hline & \multicolumn{2}{|c|}{ Trial eligible } & \multicolumn{2}{|c|}{ Trial ineligible } \\
\hline & Treated & Untreated & Treated & Untreated \\
\hline Patients $(n)$ & 113 & 31 & 178 & 206 \\
\hline \multicolumn{5}{|l|}{ Age (years) } \\
\hline Mean & $64.6 \pm 9.7$ & $71.2 \pm 11.3$ & $64.4 \pm 8.5$ & $70.8 \pm 9.8$ \\
\hline Median & 64.8 & 71.1 & 64.7 & 70.9 \\
\hline Range & $34.9-83.8$ & $43.6-87.5$ & $43.0-86.7$ & $46.2-89.7$ \\
\hline \multicolumn{5}{|l|}{$\operatorname{Sex}[n(\%)]$} \\
\hline Men & $61(54)$ & $19(61)$ & $99(55.62)$ & $113(54.85)$ \\
\hline Women & $52(46)$ & $12(39)$ & $79(44.38)$ & $93(45.15)$ \\
\hline Weight loss $>5 \%$ [ $n(\%)]$ & $45(40.9)$ & $16(53.33)$ & $75(46.01)$ & $119(63.64)$ \\
\hline \multicolumn{5}{|l|}{ Histology [n (\%)] } \\
\hline Adenocarcinoma & 77 (71.96) & $18(58.06)$ & $106(66.25)$ & $107(57.84)$ \\
\hline Squamous cell & $20(18.69)$ & 12(38.71) & $35(21.88)$ & $51(27.57)$ \\
\hline Large-cell & $6(5.61)$ & 0 & $11(6.88)$ & $10(5.41)$ \\
\hline Other NSCLC & $4(3.74)$ & $1(3.23)$ & $8(5.0)$ & $16(8.64)$ \\
\hline Mixed & 0 & 0 & 0 & $1(0.54)$ \\
\hline \multicolumn{5}{|l|}{ ECOG PS [n $(\%)]$} \\
\hline 0 & 18 & 5 & $18(11.54)$ & $5(2.66)$ \\
\hline 1 & 95 & 26 & $70(44.87)$ & $29(15.43)$ \\
\hline 2 & 0 & 0 & $54(34.62)$ & $57(30.32)$ \\
\hline 3 & 0 & 0 & $13(8.33)$ & $79(42.02)$ \\
\hline 4 & 0 & 0 & $1(0.64)$ & $18(9.57)$ \\
\hline \multicolumn{5}{|l|}{ Stage $[n(\%)]$} \\
\hline IIIB & $10(8.85)$ & $5(16.13)$ & $3(1.69)$ & $17(8.25)$ \\
\hline IV & $103(91.15)$ & $26(83.87)$ & $175(98.31)$ & $189(91.75)$ \\
\hline
\end{tabular}

NSCLC $=$ non-small-cell lung cancer; ECOG PS = Eastern Cooperative Oncology Group performance status. 
survival (4.9 months vs. 3.5 months, $p<0.001$ ); however, the difference was less dramatic than in scenario A (Table IV, Figure 2).

Importantly, despite using the relaxed criteria in scenario B, median os was superior in the eligible treated patients compared with the eligible untreated patients (10.9 months vs. 4.9 months, $p<0.0001$ ).

Scenario B included patients with brain metastasis ( $n=96), 60$ of whom were treated with systemic therapy, and 36 of whom were not. The survival analysis showed superior os in treated compared with untreated patients with brain metastasis (10.0 months vs. 5.0 months, $p=0.001$ ).

\section{Scenario Comparison}

Statistically, the median os for ineligible patients treated in scenarios A and B did not differ (10.2 months vs. 10.1 months respectively, $p=0.83$ ). A detailed multivariate analysis of the overall cohort was previously published ${ }^{29}$. That analysis indicated that omission of chemotherapy, poor performance status, and weight loss greater than $5 \%$ are associated with poor os.

\section{DISCUSSION}

Patients with NSCLC represent about $87 \%$ of all patients diagnosed with lung cancer ${ }^{30}$, and about $40 \%$ of that group present with stage IV disease ${ }^{31}$. Our results demonstrate that, whether trial-eligible or not, if patients are considered by their treating physicians to be fit for systemic therapy, they experience similar os. That finding has not been well described before. Using a simple yet logical concept, we were able to identify important clinical findings. Our study shows clearly that even trial-ineligible patients derive clinical benefit from chemotherapy. That observation highlights questions about the usefulness of strict eligibility criteria in clinical trials. Given similar survival in treated patients, whether trial-eligible or not, it could be argued that the physician's judgment is as effective as

TABLE III Proportion of treated ineligible patients in scenarios A and B

\begin{tabular}{lcccccc}
\hline \multirow{2}{*}{$\begin{array}{c}\text { Trial } \\
\text { eligibility }\end{array}$} & \multicolumn{2}{c}{$\begin{array}{c}\text { Scenario A patients } \\
{[\boldsymbol{n}(\%)]}\end{array}$} & & \multicolumn{2}{c}{$\begin{array}{c}\text { Scenario B patients } \\
{[\boldsymbol{n}(\%)]}\end{array}$} \\
\cline { 2 - 3 } & Total & Treated & & Total & Treated \\
\hline Eligible & $144(27)$ & $113(78.5)$ & & $343(65)$ & $240(70)$ \\
Ineligible & $384(73)$ & $178(46)$ & & $185(35)$ & $51(28)$ \\
\hline
\end{tabular}

trial eligibility criteria for anticipating benefit from therapy, and therefore trial eligibility criteria could be relaxed.

The stricter of our trial eligibility scenarios (scenario A) had only 4 criteria, but they were enough to exclude $73 \%$ of patients. We were limited by the data points collected, but presumably, if more extensive criteria had been applied to the dataset, more and more patients would have been excluded. That $73 \%$ is close to what has been reported previously $^{32,33}$. In fact, a study showed that the average number of trial eligibility criteria was about $23^{19}$, making it even more difficult to find eligible participants to enrol in clinical trials. Surprisingly, two studies showed that half of all exclusion criteria in clinical trials might not be backed by strong clinical evidence ${ }^{19,34,35}$.

Eligibility criteria are commonly used to achieve more homogenous populations and to minimize the chance that confounding factors will affect trial results. However, some of the exclusions are seemingly unwarranted, and variety in the enrolled patients might not significantly affect results. There is increasing evidence that patients with a PS of 2 , although having a poorer prognosis than those with a Ps of $0-1$, can still derive a significant survival advantage from systemic therapy ${ }^{36-38}$. In addition, diagnosis of a prior malignancy in advanced lung cancer patients might not be relevant, with one manuscript failing to report worse survival for such patients compared with their counterparts not having a prior diagnosis ${ }^{22}$. Furthermore, the presence of brain metastasis remains an exclusion criterion in many

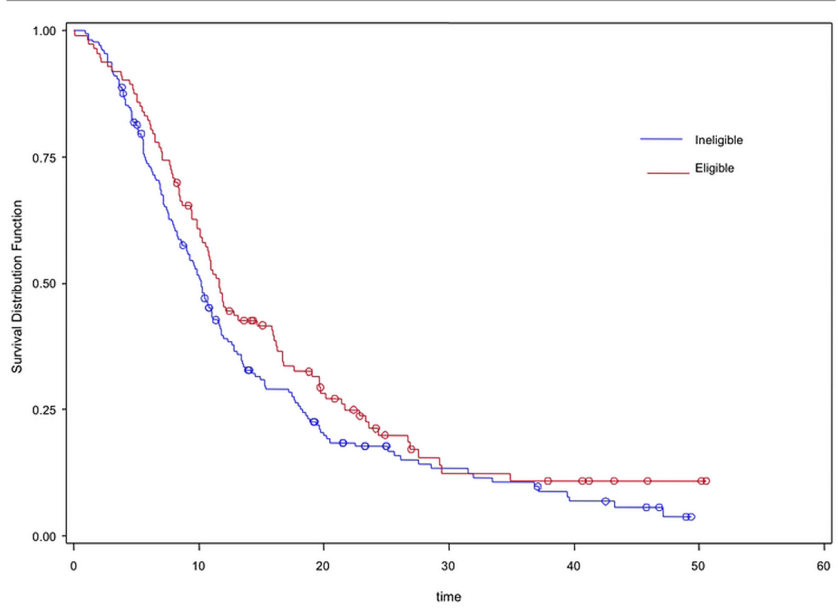

FIGURE 1 Kaplan-Meier survival curves for trial eligibility scenario A, reflecting treated eligible (red) and treated ineligible (blue) patients.

TABLE IV Overall survival in scenarios A and B, in months

\begin{tabular}{|c|c|c|c|c|c|c|c|c|}
\hline \multirow{3}{*}{$\begin{array}{c}\text { Trial } \\
\text { eligibility }\end{array}$} & \multicolumn{4}{|c|}{ Scenario A } & \multicolumn{4}{|c|}{ Scenario B } \\
\hline & \multicolumn{2}{|c|}{ Treated } & \multicolumn{2}{|c|}{ Untreated } & \multicolumn{2}{|c|}{ Treated } & \multicolumn{2}{|c|}{ Untreated } \\
\hline & Median & $95 \% \mathrm{Cl}$ & Median & $95 \% \mathrm{Cl}$ & Median & $95 \% \mathrm{Cl}$ & Median & $95 \% \mathrm{Cl}$ \\
\hline Eligible & 11.6 & 10.1 to 15.9 & 8.1 & 3.4 to 12.9 & 10.9 & 9.9 to 11.8 & 4.9 & 3.6 to 6.5 \\
\hline \multirow[t]{2}{*}{ Ineligible } & 10.2 & 8.7 to 11.5 & 3.8 & 3.2 to 4.2 & 10.1 & 6.3 to 13.4 & 3.5 & 3.1 to 4.0 \\
\hline & \multicolumn{2}{|c|}{$p=0.1$} & \multicolumn{2}{|c|}{$p=0.003$} & \multicolumn{2}{|c|}{$p=0.57$} & \multicolumn{2}{|c|}{$p<0.001$} \\
\hline
\end{tabular}


TABLE V Demographic data, scenario B

\begin{tabular}{|c|c|c|c|c|}
\hline \multirow[t]{3}{*}{ Variable } & \multicolumn{4}{|c|}{ Patient group } \\
\hline & \multicolumn{2}{|c|}{ Trial eligible } & \multicolumn{2}{|c|}{ Trial ineligible } \\
\hline & Treated & Untreated & Treated & Untreated \\
\hline Patients (n) & 240 & 103 & 51 & 134 \\
\hline \multicolumn{5}{|l|}{ Age (years) } \\
\hline Mean & $64.7 \pm 8.9$ & $70.4 \pm 11.1$ & $63.2 \pm 9.1$ & $71.2 \pm 9.1$ \\
\hline Median & 65.0 & 70.2 & 62.5 & 71.8 \\
\hline Range & $34.9-86.7$ & $43.6-88.9$ & $45.4-83.5$ & $49.1-89.7$ \\
\hline \multicolumn{5}{|l|}{$\operatorname{Sex}[n(\%)]$} \\
\hline Men & $129(53.75)$ & $57(55.34)$ & $31(60.78)$ & $75(55.79)$ \\
\hline Women & $111(46.25)$ & $46(44.66)$ & $20(39.22)$ & $59(44.03)$ \\
\hline Weight loss $>5 \%$ [ $n(\%)]$ & $99(43.23)$ & $52(53.61)$ & $21(47.73)$ & $83(69.17)$ \\
\hline \multicolumn{5}{|l|}{ Histology [n (\%)] } \\
\hline Adenocarcinoma & $152(69.09)$ & $55(58.51)$ & $31(65.96)$ & $70(57.38)$ \\
\hline Squamous cell & $46(20.91)$ & $29(30.85)$ & $9(19.15)$ & $34(27.87)$ \\
\hline Large-cell & $13(5.91)$ & $4(4.26)$ & $4(8.51)$ & $6(4.92)$ \\
\hline Other NSCLC & $9(4.09)$ & $6(6.38)$ & $3(6.38)$ & $11(9.02)$ \\
\hline Mixed & 0 & 0 & 0 & $1(0.82)$ \\
\hline \multicolumn{5}{|l|}{ ECOG PS [ $n(\%)]$} \\
\hline 0 & 35 (14.58) & $9(8.74)$ & $1(3.45)$ & $1(0.86)$ \\
\hline 1 & $155(64.58)$ & $46(44.66)$ & $10(34.48)$ & $9(7.76)$ \\
\hline 2 & $50(20.83)$ & $48(46.6)$ & $4(13.79)$ & $9(7.76)$ \\
\hline 3 & 0 & 0 & $13(44.83)$ & $79(68.1)$ \\
\hline 4 & 0 & 0 & $1(3.45)$ & $18(15.52)$ \\
\hline \multicolumn{5}{|l|}{ Stage $[n(\%)]$} \\
\hline IIIB & $13(5.42)$ & $9(8.74)$ & 0 & $13(9.7)$ \\
\hline IV & 227 (94.58) & $94(91.26)$ & $51(100)$ & $121(90.3)$ \\
\hline
\end{tabular}

NSCLC = non-small-cell lung cancer; ECOG PS = Eastern Cooperative Oncology Group performance status.

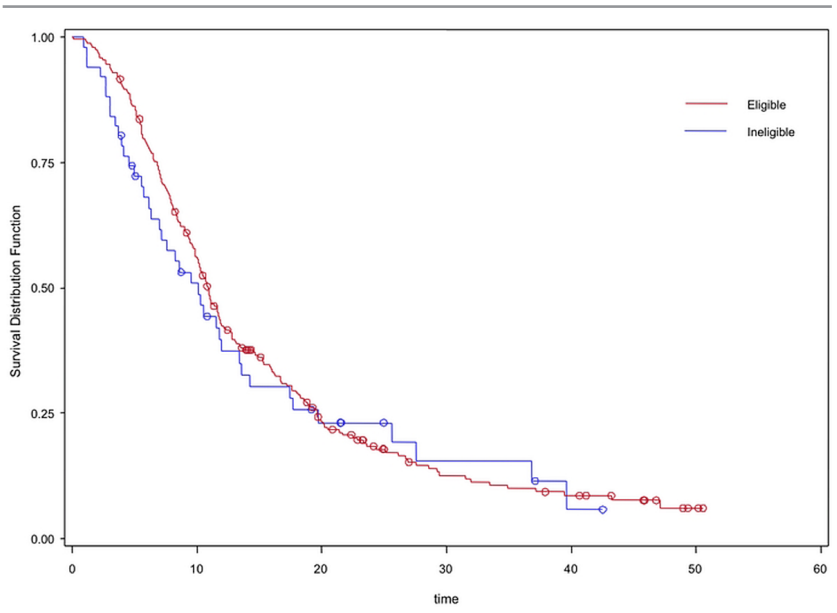

FIGURE 2 Kaplan-Meier survival curves for trial eligibility scenario B, reflecting treated eligible (red) and treated ineligible (blue) patients.

ongoing clinical trials - or in others, at least requires that central nervous system-directed therapy be given ${ }^{39}$. That criterion has clinical implications when patients present with asymptomatic millimetric central nervous system disease that might have little immediate clinical relevance, but that would require time-consuming brain radiotherapy (with its associated risks and short-term toxicities) - and a mandated radiation washout period-before the patient could subsequently enrol in a trial.

Although the present manuscript concentrates on the effect of inclusion and exclusion criteria, there are, of course, other major factors that limit clinical trial enrolment. Those factors include patient participation factors (for example, worry about uncertainty), physician participation factors (for example, problems complying with the protocol), and other factors such as the cost of clinical trials, legislation, and public health policies ${ }^{40}$. A comprehensive effort to increase trial enrolment would address all those factors.

The limitations of our study include its single-centre nature and its retrospective design, which meant that the data available for collection were limited to what had been recorded in the patient chart during management. The limited data led to the small number of eligibility criteria 
used for the study scenarios, unlike the case of a real clinical trial. Given its retrospective nature, our study could not provide prospective data about quality of life and treatment-related toxicity; however, for this same cohort of patients, we were able to show that scores from the Edmonton Symptom Assessment System were able to predict survival, as published in a separate paper ${ }^{41}$. Furthermore, our cohort did not include hospitalized patients, and it largely included patients managed before reflexive molecular profiling for EGFR mutations and $A L K$ translocations became a standard of care.

In the last century, strong initiatives set out to have what is called "proportionality" in clinical trials. "Proportionality" meant enrolling participants of different races and ages to mirror the general distribution of the cancer patient population $^{42,43}$. We would argue that ongoing initiatives are needed to further that process by reviewing trial eligibility criteria. Seeking to include patients with poorer performance status, brain metastasis, prior malignancy, or significant organ impairment should help not only to increase trial accrual, but also to make results more applicable to a general lung cancer population. The U.S. Food and Drug Administration, the American Society of Clinical Oncology, and the Friends of Cancer Research have launched an initiative to modernize clinical trial eligibility. The initiative is "designed to identify opportunities where eligibility criteria could be broadened, and ultimately influence investigators and sponsors to adjust these criteria where clinically appropriate" 44,45 .

\section{CONCLUSIONS}

The generalizability of clinical trial results can be questioned because of the high selectivity that results from restrictive eligibility criteria. Our research raises questions about whether simple clinical judgment and limited criteria could be as effective, but lead to improvements in clinical trial access and broad application of the results. We advocate a consideration of relaxed eligibility criteria to better represent the wider lung cancer patient community. Another option is to use the concept of "large simple trials."

\section{CONFLICT OF INTEREST DISCLOSURES}

We have read and understood Current Oncology's policy on disclosing conflicts of interest, and we declare that we have none.

\section{AUTHOR AFFILIATIONS}

*Department of Medicine, University of Ottawa, and ${ }^{\dagger}$ The Ottawa Hospital Research Institute, Ottawa, ON.

\section{REFERENCES}

1. Siegel RL, Miller KD, Jemal A. Cancer statistics, 2016. CA Cancer J Clin 2016;66:7-30.

2. Stewart BW, Wild CW, eds. World Cancer Report 2014. Lyon, France: International Agency for Research on Cancer; 2015.

3. Allemani C, Weir HK, Carreira H, et al. Global surveillance of cancer survival 1995-2009: analysis of individual data for $25,676,887$ patients from 279 population-based registries in 67 countries (CONCORD-2). Lancet 2015;385:977-1010.

4. Paskett ED, Cooper MR, Stark N, et al. Clinical trial enrollment of rural patients with cancer. Cancer Pract 2002;10:28-35.

5. Lara PN Jr, Higdon R, Lim N, et al. Prospective evaluation of cancer clinical trial accrual patterns: identifying potential barriers to enrollment. J Clin Oncol 2001;19:1728-33.
6. Fenton L, Rigney M, Herbst RS. Clinical trial awareness, attitudes, and participation among patients with cancer and oncologists. Community Oncol 2009;6:207-28.

7. Douillard JY, Rosell R, De Lena M, et al. Adjuvant vinorelbine plus cisplatin versus observation in patients with completely resected stage IB-IIIA non-small-cell lung cancer (Adjuvant Navelbine International Trialist Association [ANITA]): a randomised controlled trial. Lancet Oncol 2006;7:719-27.

8. Pignon JP, Tribodet H, Scagliotti GV, et al. Lung adjuvant cisplatin evaluation: a pooled analysis by the LACE collaborative group. J Clin Oncol 2008;26:3552-9.

9. Butts CA, Ding K, Seymour L, et al. Randomized phase III trial of vinorelbine plus cisplatin compared with observation in completely resected stage IB and II non-small-cell lung cancer: updated survival analysis of JBR-10. J Clin Oncol 2010;28:29-34.

10. ShepherdFA,DanceyJ, RamlauR, etal. Prospectiverandomized trial of docetaxel versus best supportive care in patients with non-small-cell lung cancer previously treated with platinumbased chemotherapy. J Clin Oncol 2000;18:2095-103.

11. Brahmer J, Reckamp KL, Baas P, et al. Nivolumab versus docetaxel in advanced squamous-cell non-small-cell lung cancer. N Engl J Med 2015;373:123-35.

12. Howerton MW, Gibbons MC, Baffi CR, et al. Provider roles in the recruitment of underrepresented populations to cancer clinical trials. Cancer 2007;109:465-76.

13. Friedman MA, Cain DF. National Cancer Institute sponsored cooperative clinical trials. Cancer 1990;65(suppl):2376-82.

14. Murthy VH, Krumholz HM, Gross CP. Participation in cancer clinical trials: race-, sex-, and age-based disparities. JAMA 2004;291:2720-6.

15. Cottin V, Arpin D, Lasset C, et al. Small-cell lung cancer: patients included in clinical trials are not representative of the patient population as a whole. Ann Oncol 1999;10:809-15.

16. Sateren WB, Trimble EL, Abrams J, et al. How sociodemographics, presence of oncology specialists, and hospital cancer programs affect accrual to cancer treatment trials. J Clin Oncol 2002;20:2109-17.

17. Vardy J, Tannock IF. Quality of cancer care. Ann Oncol 2004;15:1001-6.

18. Somer RA, Sherman E, Langer CJ. Restrictive eligibility limits access to newer therapies in non-small-cell lung cancer: the implications of Eastern Cooperative Oncology Group 4599. Clin Lung Cancer 2008;9:102-5.

19. Begg CB, Engstrom PF. Eligibility and extrapolation in cancer clinical trials. J Clin Oncol 1987;5:962-8.

20. Garcia S, Bisen A, Yan J, et al. Thoracic oncology clinical trial eligibility criteria and requirements continue to increase in number and complexity. J Thorac Oncol 2017;12:1489-95.

21. Fuks A, Weijer C, Freedman B, Shapiro S, Skrutkowska M, Riaz A. A study in contrasts: eligibility criteria in a twenty-year sample of NSABP and POG clinical trials. National Surgical Adjuvant Breast and Bowel Program. Pediatric Oncology Group. J Clin Epidemiol 1998;51:69-79.

22. Laccetti AL, Pruitt SL, Xuan L, Halm EA, Gerber DE. Effect of prior cancer on outcomes in advanced lung cancer: implications for clinical trial eligibility and accrual. J Natl Cancer Inst 2015;107:pii:djv002.

23. Gerber DE, Laccetti AL, Xuan L, Halm EA, Pruitt SL. Impact of prior cancer on eligibility for lung cancer clinical trials. $J$ Natl Cancer Inst 2014;106:pii:dju302.

24. McCusker J, WaxA, Bennett JM. Cancer patient accessions into clinical trials: a pilot investigation into some patient and physician determinants of entry. Am J Clin Oncol 1982;5:227-36.

25. Gonzalez LE, Sutton SK, Pratt C, Gilbertson M, Antonia S, Quinn GP. The bottleneck effect in lung cancer clinical trials. J Cancer Educ 2013;28:488-93. 
26. Kotwall CA, Mahoney LJ, Myers RE, DeCoste L. Reasons for non-entry in randomized clinical trials for breast cancer: a single institutional study. J Surg Oncol 1992;50:125-9.

27. LeeJY, Breaux SR. Accrual of radiotherapy patients to clinical trials. Cancer 1983;52:1014-16.

28. Simon MS, Du W, Flaherty L, et al. Factors associated with breast cancer clinical trials participation and enrollment at a large academic medical center. JClin Oncol 2004;22:2046-52.

29. Brule SY, Al-Baimani K, Jonker H, et al. Palliative systemic therapy for advanced non-small cell lung cancer: investigating disparities between patients who are treated versus those who are not. Lung Cancer 2016;97:15-21.

30. Govindan R, Page N, Morgensztern D, et al. Changing epidemiology of small-cell lung cancer in the United States over the last 30 years: analysis of the Surveillance, Epidemiologic, and End Results database. J Clin Oncol 2006;24:4539-44

31. Morgensztern D, Ng SH, Gao F, Govindan R. Trends in stage distribution for patients with non-small cell lung cancer: a National Cancer Database survey. J Thorac Oncol 2010;5:29-33.

32. Horn L, Keedy VL, Campbell N, et al. Identifying barriers associated with enrollment of patients with lung cancer into clinical trials. Clin Lung Cancer 2013;14:14-18.

33. Vardy J, Dadasovich R, Beale P, Boyer M, Clarke SJ. Eligibility of patients with advanced non-small cell lung cancer for phase III chemotherapy trials. BMC Cancer 2009;9:130.

34. Van Spall HG, Toren A, Kiss A, Fowler RA. Eligibility criteria of randomized controlled trials published in high-impact general medical journals: a systematic sampling review. JAMA 2007;297:1233-40.

35. Gerber DE, Pruitt SL, Halm EA. Should criteria for inclusion in cancer clinical trials be expanded? J Comp Eff Res 2015;4:289-91.

36. Gajra A, Marr AS, Ganti AK. Management of patients with lung cancer and poor performance status. JNatl Compr Canc Netw 2014;12:1015-25.
37. Schluckebier L, Garay OU, Zukin M, Ferreira CG. Carboplatin plus pemetrexed offers superior cost-effectiveness compared to pemetrexed in patients with advanced non-small cell lung cancer and performance status 2. Lung Cancer 2015;89:274-9.

38. Zukin M, Barrios CH, Pereira JR, et al. Randomized phase III trial of single-agent pemetrexed versus carboplatin and pemetrexed in patients with advanced non-small-cell lung cancer and Eastern Cooperative Oncology Group performance status of 2. J Clin Oncol 2013;31:2849-53.

39. McCoach CE, Berge EM, LuX, Baron AE, Camidge DR. A brief report of the status of central nervous system metastasis enrollment criteria for advanced non-small cell lung cancer clinical trials: a review of the ClinicalTrials.gov trial registry. J Thorac Oncol 2016;11:407-13.

40. Tournoux C, Katsahian S, Chevret S, Levy V. Factors influencing inclusion of patients with malignancies in clinical trials. Cancer 2006;106:258-70.

41. McGee SF, Zhang T, Jonker H, et al. The impact of baseline Edmonton Symptom Assessment Scale Scores on treatment and survival in patients with advanced non-small-cell lung cancer. Clin Lung Cancer 2018;19:e91-9.

42. Tejeda HA, Green SB, Trimble EL, et al. Representation of African-Americans, Hispanics, and whites in National Cancer Institute cancer treatment trials. J Natl Cancer Inst 1996;88:812-16.

43. Harris DJ, Douglas PS. Enrollment of women in cardiovascular clinical trials funded by the National Heart, Lung, and Blood Institute. N Engl J Med 2000;343:475-80.

44. Kim ES, Bernstein D, Hilsenbeck SG, et al. Modernizing eligibility criteria for molecularly driven trials. J Clin Oncol 2015;33:2815-20.

45. American Society of Clinical Oncology (ASCO). Initiative to modernize eligibility criteria for clinical trials launched [Web page]. Alexandria, VA: Asco; 2016. [Available at: https://www. asco.org/advocacy-policy/asco-in-action/initiative-modernizeeligibility-criteria-clinical-trials-launched; 17 May 2016] 